\title{
Fetal and infant growth predict hip geometry at 6 y old: findings from the Southampton Women's Survey
}

Nicholas C. Harvey',2, Zoe A. Cole', Sarah R. Crozier', Georgia Ntani', Pamela A. Mahon', Sian M. Robinson', Hazel M. Inskip', Keith M. Godfrey ${ }^{1,2}$, Elaine M. Dennison ${ }^{1}$ and Cyrus Cooper ${ }^{1-3}$; and the Southampton Women's Survey Study Group

BACKGROUND: We investigated relationships between early growth and proximal femoral geometry at age 6 y in a prospective population-based cohort, the Southampton Women's Survey.

METHODS: In 493 mother-offspring pairs, we assessed linear size using high-resolution ultrasound at 11, 19, and 34 wk gestation (femur length) and at birth and 1, 2, 3, 4, and 6 y (crownheel length/height). SD scores were created and conditional regression modeling generated mutually independent growth variables. Children underwent hip dual-energy X-ray absorptiometry (DXA) at 6 ; hip structure analysis software yielded measures of geometry and strength.

RESULTS: There were strong associations between early linear growth and femoral neck section modulus (Z) at $6 y$, with the strongest relationships observed for femur growth from 19 to 34 wk gestation $\left(\beta=0.26 \mathrm{~cm}^{3} / \mathrm{SD}, P<0.0001\right)$, and for height growth from birth to 1 y $\left(\beta=0.25 \mathrm{~cm}^{3} / \mathrm{SD}, P<0.0001\right)$ and 1 to 2 y $\left(\beta=0.33 \mathrm{~cm}^{3} / \mathrm{SD}, P<0.0001\right)$, with progressively weaker relationships over years $3\left(\beta=0.23 \mathrm{~cm}^{3} / \mathrm{SD}, P=0.0002\right)$ and $4\left(\beta=0.10 \mathrm{~cm}^{3} / \mathrm{SD}, P=0.18\right)$.

CONCLUSION: These results demonstrate that growth before age 3 y predicts proximal femoral geometry at 6 y old. These data suggest critical periods in which there is capacity for longterm influence on the later skeletal growth trajectory.

$\mathbf{R}^{\mathrm{i}}$ isk of osteoporotic fracture in adulthood is strongly associated with bone mass (a composite measure with contributions from both size and volumetric density) (1); more recently, it has been recognized that the shape of the proximal femur is an additional risk factor for femoral neck fracture (2-7). There is accumulating evidence that adult bone mass (8) and risk of hip fracture might be partly dependent on growth in early life $(9,10)$ and that this relationship might be mediated partly through an effect on the geometry of the proximal femur assessed by dual-energy X-ray absorptiometry (DXA) techniques in older age (11). We reasoned that if this hypothesis were correct, then such relationships between early growth and proximal femoral geometry might already be manifested in childhood. Although data are scant, there is some evidence that proximal femoral shape might be modified by postnatal exposures such as physical activity in young childhood (12); furthermore, we have demonstrated that the longer-term trajectory of skeletal growth might be influenced by factors acting in utero or in early childhood (13-17). Finally, we have found that growth velocity at different points in development through intrauterine and postnatal life is associated with bone mineral accrual by 4 y old $(18,19)$. Taking these childhood findings together with the previously observed associations between early growth and adult hip geometry, we hypothesized that growth velocity in utero and early childhood might positively predict measures of femoral neck strength, assessed by DXA at $6 \mathrm{y}$ old, in children born to the Southampton Women's Survey, an ongoing longitudinal mother-offspring cohort.

\section{RESULTS}

\section{Characteristics of the Children}

There were 493 children (255 boys) with complete usable DXA data. The characteristics of the mothers and children are shown in Tables 1 and 2 , respectively.

As compared with the mothers of children born to the Southampton Women's Survey during the same time frame but who did not have DXA scans at 6 y, the mothers of children who did have DXA assessments were, on average, slightly older at the birth of their child (mean age $30.3 \mathrm{vs.} 30.0 \mathrm{y}$, respectively, $P=0.07$ ), better educated (60\% with higher degree vs. $55 \%$, respectively, $P=0.045)$, and smoked slightly less ( $43 \%$ smoked before pregnancy vs. $48 \%$, respectively, $P=0.081$ ).

Linear Growth and DXA Measurement of Hip Size, Density, and Strength at $6 y$

After adjustment for child's age, sex, and milk intake, linear growth at all fetal and infant time intervals was positively related to total hip bone area and bone mineral content (BMC), and to femoral narrow neck cross-sectional area, cross-sectional moment of inertia, and section modulus ( $Z$ ). These results are summarized in Table 3 and Figure $1 . \mathrm{Z}$ was associated most strongly with growth in late gestation (19-34-wk linear growth and $\mathrm{Z}$ at $6 \mathrm{y}: \beta=0.26 \mathrm{~cm}^{3} / \mathrm{SD}, P<0.0001$ compared with $11-19-$ wk linear

${ }^{1}$ Medical Research Council Lifecourse Epidemiology Unit, University of Southampton, Southampton, UK; ${ }^{2}$ National Institute for Health Research Southampton Biomedical Research Centre, University of Southampton, and University Hospital Southampton NHS Foundation Trust, Southampton General Hospital, Southampton, UK; ${ }^{3}$ National Institute for Health Research Musculoskeletal Biomedical Research Unit, University of Oxford, Oxford, UK. Correspondence: Cyrus Cooper (cc@mrc.soton.ac.uk) 
Table 1. Characteristics of the parents

\begin{tabular}{|c|c|c|}
\hline \multirow[b]{2}{*}{ Characteristic } & Mothers & \multirow[b]{2}{*}{ SD or IQR } \\
\hline & $\begin{array}{l}\text { Mean or median } \\
\quad \text { or } n(\%)\end{array}$ & \\
\hline Age at birth of the child (y) & 30.3 & 3.7 \\
\hline Height (cm) & 163.7 & 6.5 \\
\hline BMI prepregnancy $\left(\mathrm{kg} / \mathrm{m}^{2}\right)$ & 26.0 & $24.1-28.8$ \\
\hline Smoking prepregnancy ( $(\%))$ & $212(43 \%)$ & \\
\hline \multicolumn{3}{|l|}{ Ethnicity } \\
\hline White $(n(\%))$ & $474(96.2 \%)$ & \\
\hline Other $(n(\%))$ & $19(3.9 \%)$ & \\
\hline LP triceps skinfold thickness (mm) & $20.8^{a}$ & $16.5-25.7^{a}$ \\
\hline Nulliparous (n (\%)) & $224(45.4)$ & \\
\hline LP smoking ( $n(\%))$ & $65(13.3)$ & \\
\hline \multicolumn{3}{|l|}{ LP walking speed ( $n(\%))$} \\
\hline Very slow & $82(16.8)$ & \\
\hline Stroll at an easy pace & $242(49.5)$ & \\
\hline Normal speed & $133(27.2)$ & \\
\hline Fairly brisk & $30(6.1)$ & \\
\hline Fast & $2(0.4)$ & \\
\hline \multicolumn{3}{|l|}{ Social class } \\
\hline Professional & $22(4.6)$ & \\
\hline Management/technical & $190(39.4)$ & \\
\hline Skilled nonmanual & $175(36.3)$ & \\
\hline Skilled manual & $35(7.3)$ & \\
\hline Partly skilled & $54(11.2)$ & \\
\hline Unskilled & $6(1.2)$ & \\
\hline \multicolumn{3}{|l|}{ Educational attainment } \\
\hline None-O levels & $197(40.0)$ & \\
\hline A levels-degree & $296(60.0)$ & \\
\hline Paternal height (cm) & 176.6 & 7.6 \\
\hline Paternal BMI $\left(\mathrm{kg} / \mathrm{m}^{2}\right)$ & $24.3^{\mathrm{a}}$ & $22.4-27.5^{\mathrm{a}}$ \\
\hline
\end{tabular}

$I Q R$, interquartile range; $L P$, late pregnancy.

aMedian/IQR.

Table 3. Length from birth to $4 \mathrm{y}$ and hip geometry at $6 \mathrm{y}$ (adjusted for daily milk intake at $6 \mathrm{y}$ )

\begin{tabular}{|c|c|c|c|c|c|c|c|c|c|c|c|}
\hline & \multicolumn{4}{|c|}{ Total hip } & \multicolumn{4}{|c|}{ Narrow neck } & \multicolumn{3}{|c|}{ Intertrochanter } \\
\hline 11-19 wk: Conditional length $z$-score & $0.16^{* *}$ & $0.13^{*}$ & 0.049 & -0.028 & 0.1 & 0.037 & 0.11 & 0.099 & $0.12^{*}$ & 0.11 & $0.15^{*}$ \\
\hline $0-1$ y: Conditional length $z$-score & $0.34^{* * *}$ & $0.24 * * *$ & 0.00039 & $-0.16^{* *}$ & $0.22^{* * *}$ & 0.077 & $0.28^{* * *}$ & $0.25^{* * *}$ & $0.19^{* *}$ & $0.26^{* * *}$ & $0.29 * * *$ \\
\hline $1-2 y$ : Conditional length $z$-score & $0.40^{* * *}$ & $0.39^{* * *}$ & $0.21^{* * *}$ & 0.075 & $0.34^{* * *}$ & $0.22^{* * *}$ & $0.34^{* * *}$ & $0.33^{* * *}$ & $0.33^{* * *}$ & $0.35^{* * *}$ & $0.35^{* * *}$ \\
\hline 3-4 y: Conditional length $z$-score & 0.12 & $0.14^{*}$ & 0.094 & 0.038 & 0.11 & 0.077 & 0.11 & 0.098 & $0.15^{*}$ & 0.13 & $0.15^{*}$ \\
\hline 4-6y: Conditional length z-score & $0.18^{* *}$ & $0.16^{*}$ & 0.076 & -0.02 & 0.13 & 0.093 & 0.11 & 0.14 & $0.16^{*}$ & $0.18^{* *}$ & $0.19^{* *}$ \\
\hline
\end{tabular}

Table shows the standardized $\beta$ (SD/SD) and significance level.

aBMD, areal bone mineral density; BA, bone area; BMC, bone mineral content; CSA, cross-sectional area; CSMI, cross-sectional moment of inertia; $C T$, cortical thickness;

scBMC, size-corrected BMC; Z, femoral neck section modulus.

${ }^{*} P<0.05 ;{ }^{* *} P<0.01 ; * * * P<0.001$ 


\section{Articles $\mid$ Harveyet al.}
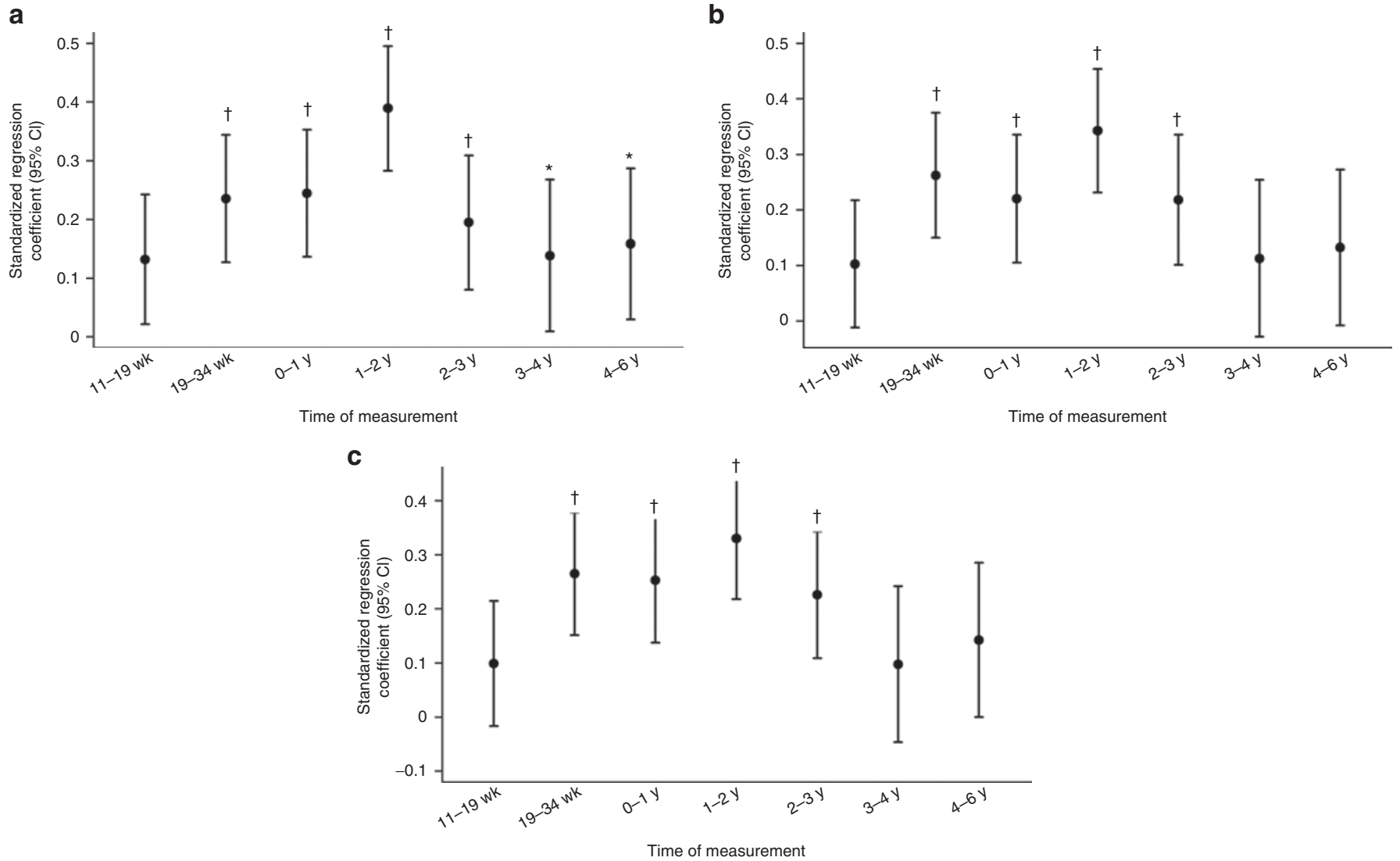

Figure 1. Plot of standardized regression coefficients for (a) total hip bone mineral content, (b) narrow femoral neck cross-sectional area, and (c) narrow femoral neck section modulus on conditional linear growth 11 wk to 6 y. Growth variables are all independent. ${ }^{*} P<0.05$; ${ }^{+} P<0.001$. Cl, confidence interval.

growth and $\left.\mathrm{Z}: \beta=0.10 \mathrm{~cm}^{3} / \mathrm{SD}, P=0.09\right)$, and in the first $2 \mathrm{y}$ of postnatal life $\left(0-1\right.$-y linear growth and $\mathrm{Z}: \beta=0.25 \mathrm{~cm}^{3} / \mathrm{SD}, P<$ $\left.0.0001 ; 1-2 \mathrm{y}: \beta=0.33 \mathrm{~cm}^{3} / \mathrm{SD}, P<0.0001\right)$, with progressively weaker relationships over years $3\left(\beta=0.23 \mathrm{~cm}^{3} / \mathrm{SD}, P=0.0002\right)$ and $4\left(\beta=0.10 \mathrm{~cm}^{4} / \mathrm{SD}, P=0.18\right)$. Relationships between growth and size corrected measures of bone mineral (areal bone mineral density and size-corrected BMC) were rather weaker, the most robust association being between areal bone mineral density and linear growth in the second year of postnatal life. Cortical thickness at the femoral narrow neck was positively associated with linear growth from 19 to $34 \mathrm{wk}(\beta=0.22 \mathrm{~cm} / \mathrm{SD}, P=0.0002)$ and from 1 to 2 y $(\beta=0.22 \mathrm{~cm} / \mathrm{SD}, P=0.0002)$. Relationships between growth and cross-sectional area, cross-sectional moment of inertia, and $\mathrm{Z}$ at the intertrochanteric site were similar to those observed at the narrow neck site. These associations were similar when analyzed separately by offspring sex. Figure 2 summarizes the percentage of subjects who remained in the same third of the length growth distribution over each subsequent growth period; this demonstrates a relatively steady crossing between thirds of the distribution antenatally but then a progressive decrease in crossing postnatally.

Influence of Maternal Anthropometry and Lifestyle, and Child's Body Composition

We investigated the role of parental factors, some of which have been previously associated with offspring intrauterine

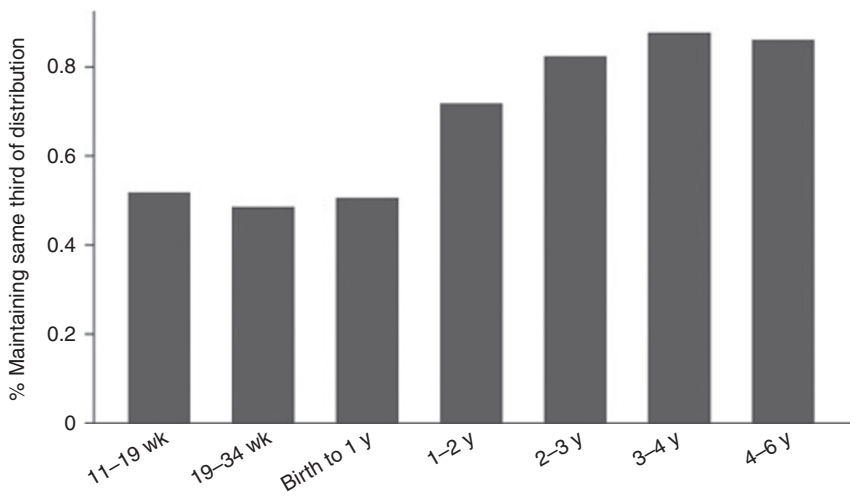

Figure 2. Percentage of participants remaining in the same third of linear size over each subsequent time interval.

bone mineral accrual, that might influence fetal growth and childhood skeletal development through genetic and/or environmental effects (maternal height, ethnicity, social class, education, prepregnancy smoking and BMI, and triceps skinfold thickness, and walking speed and smoking in late pregnancy; and paternal height and BMI) together with offspring birth order. Of these, associations with early growth and 6-y DXAderived hip indexes were observed only for maternal height, and more weakly, for paternal height (Table 4). Therefore, maternal height was positively related to growth up to $3 \mathrm{y}$, as 
Table 4. Parental height and offspring growth and 6-y hip measures

\begin{tabular}{|c|c|c|c|c|c|c|c|c|c|c|c|c|c|c|c|}
\hline & \multicolumn{7}{|c|}{ Linear growth } & \multicolumn{4}{|c|}{ Total hip } & \multicolumn{4}{|c|}{ Narrow neck } \\
\hline & $\begin{array}{c}11-19 \\
w k\end{array}$ & $\begin{array}{c}19-34 \\
w k\end{array}$ & $0-1$ y & $1-2 y$ & $2-3 y$ & $3-4 y$ & $4-6 y$ & BA & BMC & aBMD & scBMC & CSA & CT & CSMI & Z \\
\hline Paternal height & 0.01 & $0.02 *$ & $0.02 *$ & 0.01 & $0.02 *$ & 0.0 & 0.0 & $0.01^{*}$ & 0.01 & 0.0 & 0.0 & 0.01 & 0.01 & 0.01 & $0.01^{*}$ \\
\hline
\end{tabular}

Standardized $\beta$ (SD/SD) and significance level.

aBMD, areal bone mineral density; BA, bone area; BMC, bone mineral content; CSA, cross-sectional area; CSMI, cross-sectional moment of inertia; CT, cortical thickness; sCBMC, sizecorrected BMC; Z, femoral neck section modulus.

${ }^{*} P<0.05$; ${ }^{* *} P<0.01 ;{ }^{* * *} P<0.001$

well as to 6-y hip size, shape, and strength; paternal height was positively associated with growth in late pregnancy and the first year of postnatal life. The inclusion of parental height, however, as with all other parental measures and offspring birth order, did not materially alter the observed relationships between growth and 6-y hip bone outcomes. In further analyses including childhood body composition at age 6 y (percentage lean or percentage fat) as a covariate, relationships between early growth and 6-y hip structure remained robust.

\section{DISCUSSION}

We have demonstrated that early growth predicts proximal femoral size, mineralization, geometry, and strength at $6 \mathrm{y}$ old, independent of current body composition. The relationships are particularly strong for linear growth in late pregnancy and in the first 2-3y of postnatal life, suggesting that these might be critical periods in which there is capacity for long-term influence on the later skeletal growth trajectory.

The strengths of our study included the recruitment of children from a free-living population cohort and use of objective measures of body composition and bone indexes. There are, however, several limitations to our study. Intrauterine ultrasound measurements are prone to a certain amount of error, but data were collected by two experienced operators following internationally agreed guidelines (20) and repeatability was good (coefficient of variation $0.6 \%$ for femur length). The children we studied in the current analysis represent a subset of the original cohort but did not differ at birth or $1 \mathrm{y}$ old from those who did not undergo a 6-y visit. Mothers of children assessed at $6 \mathrm{y}$ were similar to mothers of those children who were not assessed, but, on average, had slightly higher levels of education. The analysis is based on internal comparisons, however, and it is therefore difficult to envisage how this would have spuriously created an association between growth and hip geometry. Second, measurement of bone mineral in young children by DXA is impeded by their low absolute BMC and tendency to move. However, movement artifact was modest and uniform across the cohort. We used appropriate pediatric software and those few children with excessive movement artifact were excluded from the analysis. Studies of DXA in piglets in which true bone mass was quantified after ashing have demonstrated the accuracy of DXA assessment in small animals $(21,22)$. The hip structure analysis software assumes a constant volumetric bone mineral density at the tissue level; this will systematically influence the absolute measurements obtained from the software but should have no effect on the ranking of the individuals, and therefore should not have influenced our results. Indeed, this technique has been used successfully in a young pediatric cohort (12). It is not possible, in this observational cohort study, to deduce whether observed relationships are causal, or whether they are explained by genetic or environmental factors or by an interaction between the two. Finally, owing to the high percentage of white mothers in the cohort (96\%), our study was not powered to enable elucidation of any ethnicity-specific differences in the relationships between early growth and childhood hip geometry.

To our knowledge, this is the first longitudinal study to assess hip geometry assessed by DXA in relation to growth from early gestation to late infancy using objective measures such as ultrasound. Given the difficulties of setting up suitable prospective cohorts, many previous studies, particularly those of intrauterine growth, have been cross-sectional in nature. Much of the seminal work in this area has been carried out by Tanner and colleagues $(23,24)$, using a combination of crosssectional measurements of postnatal fetal size at various gestations and longitudinal measurements of children. The patterns of growth deduced from such studies are compatible with the findings of our current and previous work (18), in which we demonstrated positive associations between growth in linear size from $19 \mathrm{wk}$ gestation to $3 \mathrm{y}$ postnatal life and whole-body bone size, mineral content, and areal density. Similar to the relationships observed in our current study, the magnitude of the association reduced with each successive postnatal year. However, in this earlier study, we were not able to examine structural parameters at the hip.

On the basis of these and other studies, after peak growth velocity is achieved in the last trimester, there appears to be a period of growth velocity reduction, particularly for weight, in the very last part of pregnancy, followed by a further modulation of growth velocity over the first couple of years of life. This slowing in late pregnancy is thought to be a result of the increasing fetal size outstripping placental capacity and acts to limit fetal size, allowing the baby to be safely delivered through the birth canal (23). Therefore, if a Shire horse is crossed with a Shetland pony, the offspring is born small when the mother is a Shetland pony and large when the mother is a Shire horse (25). When the offspring is fully grown, it is a similar size from either combination, which is midway between the two parents. This late pregnancy deviation from the earlier growth trajectory appears to be sensitive to environmental factors such as 
maternal fat stores, physical activity, and smoking $(14,26)$; over the first 2 y of postnatal life, studies have demonstrated that a considerable proportion of infants change position in the size distribution relative to their peers $(24,27)$. Clinical observations, results from analytical investigations such as the Karlberg infant-child-puberty model $(28,29)$, and our current and previous data all suggest that the first 2-3 y of postnatal life are critical for setting up the later growth trajectory. Indeed, in our study, as in our previous work (18), the percentage of children who remained in the same third of the length distribution relative to their peers across each subsequent time interval increased progressively with each subsequent postnatal time interval, consistent with gradual settling onto a sustained childhood growth trajectory.

Our previous work has suggested that growth in early life, both in utero and during infancy, predicts adult $\operatorname{BMC}(8,30)$ as well as the risk of hip fracture $(9,10)$. Furthermore, in a cohort of 333 adults from Hertfordshire aged 60-75 y, we found positive associations between weight at $1 \mathrm{y}$ and femoral neck width and intertrochanteric cross-sectional moment of inertia, the former relationship persisting after adjustment for adult body size (11). These results suggest that the associations between early growth and risk of hip fracture might be mediated by alterations to proximal femoral geometry. The shape of the proximal femur has been shown to predict fracture risk in adult populations (2-7); greater femoral neck length has consistently been associated with increased fracture risk, but relationships between incident fracture and femoral neck width have been reported in both directions (2-5). In those studies that have included derived measurements of mechanical strength, such as section modulus, these have generally been negatively related to future fracture risk (3-5), as has cortical thickness (2-4). We believe that ours is the first study to look at growth prenatally and in early childhood in relation to later childhood bone geometry. Our current results are consistent with relationships between early growth and proximal femoral geometry manifesting at an early stage in postnatal life, and taken with the results from the Hertfordshire cohort (11), these associations may have important implications for risk of hip fracture in late adulthood.

There is some evidence that habitual physical activity and body composition during postnatal life may influence hip geometry (12), but data from exercise intervention studies, although sometimes demonstrating a positive effect on bone mineral accrual $(31,32)$, have not consistently shown effects on proximal femoral geometry (33-36). It is likely that, in contrast to mineralization, the shape of the hip requires a much longer time to change in response to modulation of physical activity than allowed for in these studies; alterations might therefore reflect ongoing loading from muscle related to habitual physical activity. However, the results we observed were not materially influenced by adjustment for whole-body percentage lean or fat mass at $6 \mathrm{y}$, consistent with a mechanism at least partly independent of current body composition.

In conclusion, we have identified periods of linear growth in late intrauterine and early postnatal life that are particularly strongly related to later proximal femoral size, mineralization, geometry, and strength at $6 \mathrm{y}$ old, independent of childhood body composition. These findings are consistent with our previous data and both clinical and theoretical models of infant growth, and suggest that these might be critical periods in which there is capacity for long-term influence on the later skeletal growth trajectory and thus adult fracture risk.

\section{METHODS}

\section{Participants}

The Southampton Women's Survey is a prospective cohort study of 12,583 women aged $20-34$ y recruited from the general population (37). At enrollment, the participants were characterized in detail in terms of diet, lifestyle, health, physical activity (by intervieweradministered questionnaire), and anthropometric measurements. A total of 3,159 of these women were followed through a subsequent pregnancy and delivered a live-born infant. The children are being followed and characterized, with samples of children assessed at birth, and at 4 and $6 y$, and in later childhood. Of the 1,268 eligible families contacted for a $6-y$ follow-up during the study period (6th birthday up to the end of 2009), 530 attended for DXA, forming the cohort presented in this article. The association between fat mass, bone size, and volumetric density in this cohort has been reported previously (17).

\section{Prenatal Ultrasound Scanning}

Because this was a population survey, no inclusion criteria were set for the pregnancy study other than singleton pregnancy and ability to provide informed consent. At 11, 19, and 34 wk gestation, the women underwent high-resolution ultrasound scanning using a Kretz Voluson 730 (GE Kretz Ultrasound, Tiefenbach, Austria) system or an Acuson Sequoia 512 (Siemens, Erlangen, Germany) system; the two systems were cross-calibrated. After establishing correct positioning according to standard anatomical landmarks, measurements of crown-rump length (at $11 \mathrm{wk}$ gestation) and femur length (obtained at 19 and $34 \mathrm{wk}$ ) were made on the frozen images using electronic calipers by the two operators, according to internationally accepted and validated methodology (20). Each measurement was performed in triplicate, and the mean value was used for analysis.

\section{Postnatal Growth}

Crown-heel length at birth was measured using a neonatometer (Harpenden, Wrexham, UK). Children were assessed at $6 \mathrm{mo}$ and at $1,2,3,4$, and $6 y$ with a home visit from a research nurse. Information on diet, lifestyle, illness, and medication was collected, and anthropometric measurements were performed. Crown-heel length at $1 \mathrm{y}$ was measured using an infantometer (Seca, Birmingham, UK). Height was measured at 23 , 4, and 6 y using a Leicester height measure (Seca).

\section{6-y DXA Assessment}

The mother and child were invited to visit the Osteoporosis Centre at Southampton General Hospital for the assessment of bone mass and body composition. At this visit, written informed consent for the DXA scan was obtained from the mother, father, or guardian. The child's height (using a Leicester height measure; Seca) and weight, using calibrated digital scales (Seca) were measured. Whole-body (including body composition) and total hip scans were obtained using a Hologic Discovery A instrument with APEX 3.0 software (Hologic, Bedford, MA). To encourage compliance, a sheet with appropriate pictures was laid on the couch, and to help reduce movement artifact, the children were shown a suitable DVD. The total radiation doses for the scans were as follows: whole-body (pediatric scan mode), $4.7 \mu \mathrm{Sv}$, and hip, $7.3 \mu \mathrm{Sv}$. The manufacturer's coefficient of variation for the instrument was $0.75 \%$ for whole-body bone mineral density, and the experimental coefficient of variation when a spine phantom was repeatedly scanned in the same position 16 times-in a single session with no repositioning-was $0.68 \%$. All scans were checked for movement and clothing artifact, resulting in 493 scans suitable for analysis. 


\section{Hip Structure Analysis}

An interactive computer program (Hip Structural Analysis; Hologic) was used to derive a number of structural variables from the femoral DXA scans. The Hip Structural Analysis software derives geometry of the load-supporting surface by employing a projection principle first described by Martin and Burr (38); the detailed methodology has been published previously, demonstrating a coefficient of variation of $\sim 2-4 \%$, depending on exact measure (39). Using this technique, structural indexes may be derived at the narrow femoral neck and intertrochanteric regions. The hip measurements obtained at 6 y old, using the standard automated software algorithm to define region of interest, included total hip bone area, BMC, areal bone mineral density, and, as the basis for size-corrected bone mineral density, BMC adjusted for bone area, height, and weight; cortical thickness, cross-sectional area, cross-sectional moment of inertia, and section modulus $(Z)$ (a measure of bending strength) were estimated at both the narrow femoral neck and intertrochanteric regions using the automated hip structure analysis software with minimal operator adjustment.

\section{Statistical Analysis}

All women had a reliable date of last menstrual period. All variables were checked for normality. Nonnormally distributed variables were transformed logarithmically. Differences between boys and girls for all size and outcome variables at each time point were explored using Student's $t$-test and Wilcoxon rank-sum test where appropriate. Within-group $z$-scores for the ultrasound-derived measures of fetal size were generated and adjusted for sex and gestational age at which the measurement was taken. The measures of linear size used were crown-rump length (11 wk gestation), femur length (19 and 34 wk gestation), crown-heel length (birth and 1 y postnatally), and standing height British Growth Foundation $z$-score (2-6 y postnatally). Conditional models of change were built using linear regression analysis: therefore, linear size $z$-score at $11 \mathrm{wk}$ was the starting point. Conditional change in linear size $z$-score from 11 to $19 \mathrm{wk}$ is equivalent to the standardized residuals resulting from the linear regression model of $z$-score at $19 \mathrm{wk}$ on $z$-score at $11 \mathrm{wk}$. The conditional change in $z$-score from 19 to $34 \mathrm{wk}$ is given from the standardized residuals obtained from regressing $z$-score at $34 \mathrm{wk}$ on both $z$-score at $19 \mathrm{wk}$ and $z$-score at $11 \mathrm{wk}$ simultaneously. This process was continued for each subsequent time point, resulting in measures of conditional growth that are mutually uncorrelated and yielding standard deviate scores that can be used to compare relationships between growth at different time intervals and bone measures at 6 y (adjusted for sex and age).

Linear regression methods were used to explore the relationship between the growth measurements and hip geometry at 6 y old, using Stata V11.1 (Stata, College Station, TX). The resulting $\beta$ term represents the change in outcome (units dependent on individual measure) per SD change in the predictor.

The Southampton Women's Survey was approved by the Southampton and South West Hampshire Local Research Ethics Committee. Written consent was obtained from parents/guardians of all participants.

\section{ACKNOWLEDGMENTS}

Southampton Women's Survey Study Group: Pat Taylor, Linda J. Barron, Corinne E. Nisbet, Mark Hanson, David J. Barker, and Catherine M. Law. We thank the mothers who gave us their time and a team of dedicated research nurses and ancillary staff for their assistance. We thank Gill Strange and Ruth Fifield for helping to prepare the manuscript.

\section{STATEMENT OF FINANCIAL SUPPORT}

This work was supported by grants from the Medical Research Council, British Heart Foundation, Arthritis Research UK, National Osteoporosis Society, International Osteoporosis Foundation, Cohen Trust, National Institute for Health Research Southampton Biomedical Research Centre, University of Southampton and University Hospital Southampton NHS Foundation Trust, and NIHR Musculoskeletal Biomedical Research Unit, University of Oxford. The research leading to these results has received funding from European Union's Seventh Framework Programme (FP7/2007-2013), Project Early Nutrition (289346).

Disclosure: All authors report no conflict of interest.

\section{REFERENCES}

1. Marshall D, Johnell O, Wedel H. Meta-analysis of how well measures of bone mineral density predict occurrence of osteoporotic fractures. BMJ 1996;312:1254-9.

2. El-Kaissi S, Pasco JA, Henry MJ, et al. Femoral neck geometry and hip fracture risk: the Geelong osteoporosis study. Osteoporos Int 2005;16:1299303.

3. Kaptoge S, Beck TJ, Reeve J, et al. Prediction of incident hip fracture risk by femur geometry variables measured by hip structural analysis in the study of osteoporotic fractures. J Bone Miner Res 2008;23:1892-904.

4. Ito M, Wakao N, Hida T, et al. Analysis of hip geometry by clinical CT for the assessment of hip fracture risk in elderly Japanese women. Bone 2010;46:453-7.

5. LaCroix AZ, Beck TJ, Cauley JA, et al. Hip structural geometry and incidence of hip fracture in postmenopausal women: what does it add to conventional bone mineral density? Osteoporos Int 2010;21:919-29.

6. Im GI, Lim MJ. Proximal hip geometry and hip fracture risk assessment in a Korean population. Osteoporos Int 2011;22:803-7.

7. Center JR, Nguyen TV, Pocock NA, et al. Femoral neck axis length, height loss and risk of hip fracture in males and females. Osteoporos Int 1998;8:75-81.

8. Dennison EM, Syddall HE, Sayer AA, Gilbody HJ, Cooper C. Birth weight and weight at 1 year are independent determinants of bone mass in the seventh decade: the Hertfordshire cohort study. Pediatr Res 2005;57:582-6.

9. Cooper C, Eriksson JG, Forsén T, Osmond C, Tuomilehto J, Barker DJ. Maternal height, childhood growth and risk of hip fracture in later life: a longitudinal study. Osteoporos Int 2001;12:623-9.

10. Javaid MK, Eriksson JG, Kajantie E, et al. Growth in childhood predicts hip fracture risk in later life. Osteoporos Int 2011;22:69-73.

11. Javaid MK, Lekamwasam S, Clark J, et al.; Hertfordshire Cohort Study Group. Infant growth influences proximal femoral geometry in adulthood. J Bone Miner Res 2006;21:508-12.

12. Janz KF, Burns TL, Levy SM, et al. Everyday activity predicts bone geometry in children: the iowa bone development study. Med Sci Sports Exerc 2004;36:1124-31.

13. Godfrey K, Walker-Bone K, Robinson S, et al. Neonatal bone mass: influence of parental birthweight, maternal smoking, body composition, and activity during pregnancy. J Bone Miner Res 2001;16:1694-703.

14. Harvey NC, Javaid MK, Arden NK, et al.; SWS Study Team. Maternal predictors of neonatal bone size and geometry: the Southampton Women's Survey. J Dev Orig Health Dis 2010;1:35-41.

15. Javaid MK, Crozier SR, Harvey NC, et al.; Princess Anne Hospital Study Group. Maternal vitamin D status during pregnancy and childhood bone mass at age 9 years: a longitudinal study. Lancet 2006;367:36-43.

16. Harvey NC, Javaid MK, Poole JR, et al.; Southampton Women's Survey Study Group. Paternal skeletal size predicts intrauterine bone mineral accrual. J Clin Endocrinol Metab 2008;93:1676-81.

17. Cole ZA, Harvey NC, Kim M, et al.; Southampton Women's Survey Study Group. Increased fat mass is associated with increased bone size but reduced volumetric density in pre pubertal children. Bone 2012;50:5627.

18. Harvey NC, Mahon PA, Kim M, et al.; SWS Study Group. Intrauterine growth and postnatal skeletal development: findings from the Southampton Women's Survey. Paediatr Perinat Epidemiol 2012;26:34-44.

19. Harvey NC, Mahon PA, Robinson SM, et al.; SWS Study Group. Different indices of fetal growth predict bone size and volumetric density at 4 years of age. J Bone Miner Res 2010;25:920-7.

20. Chitty LS, Altman DG, Henderson A, Campbell S. Charts of fetal size: 4 . Femur length. Br J Obstet Gynaecol 1994;101:132-5.

21. Brunton JA, Bayley HS, Atkinson SA. Validation and application of dualenergy $\mathrm{x}$-ray absorptiometry to measure bone mass and body composition in small infants. Am J Clin Nutr 1993;58:839-45.

22. Brunton JA, Weiler HA, Atkinson SA. Improvement in the accuracy of dual energy x-ray absorptiometry for whole body and regional analysis of body composition: validation using piglets and methodologic considerations in infants. Pediatr Res 1997;41(4 Pt 1):590-6. 


\section{Articles | Harveyet al.}

23. Tanner JM. Growth before birth. In: Foetus into Man: Physical growth From conception to maturity. 2nd edition. Ware, England: Castlemead Publications, 1989:36-50.

24. Tanner JM. The organisation of the growth process. In: Foetus into Man: Physical Growth from Conception to Maturity. 2nd edn. Ware, England: Castlemead Publications, 1989:165-177.

25. Walton A, Hammond J. The maternal effects on growth and conformation in Shire horse-Shetland pony crosses. Proc R Soc Lond (Biol) 1938; 125:311-35.

26. Harvey NC, Poole JR, Javaid MK, et al.; SWS Study Group. Parental determinants of neonatal body composition. J Clin Endocrinol Metab 2007;92:523-6.

27. Smith DW, Truog W, Rogers JE, et al. Shifting linear growth during infancy: illustration of genetic factors in growth from fetal life through infancy. J Pediatr 1976;89:225-30.

28. Karlberg J. A biologically-oriented mathematical model (ICP) for human growth. Acta Paediatr Scand Suppl 1989;350:70-94.

29. Karlberg J, Engström I, Karlberg P, Fryer JG. Analysis of linear growth using a mathematical model. I. From birth to three years. Acta Paediatr Scand 1987;76:478-88.

30. Cooper C, Cawley M, Bhalla A, et al. Childhood growth, physical activity, and peak bone mass in women. J Bone Miner Res 1995;10: $940-7$.

31. Morris FL, Naughton GA, Gibbs JL, Carlson JS, Wark JD. Prospective tenmonth exercise intervention in premenarcheal girls: positive effects on bone and lean mass. J Bone Miner Res 1997;12:1453-62.
32. Bradney M, Pearce G, Naughton G, et al. Moderate exercise during growth in prepubertal boys: changes in bone mass, size, volumetric density, and bone strength: a controlled prospective study. J Bone Miner Res 1998;13:1814-21.

33. Alwis G, Linden C, Stenevi-Lundgren S, et al. A school-curriculum-based exercise intervention program for two years in pre-pubertal girls does not influence hip structure. Dyn Med 2008;7:8.

34. Weeks BK, Young CM, Beck BR. Eight months of regular in-school jumping improves indices of bone strength in adolescent boys and Girls: the POWER PE study. J Bone Miner Res 2008;23:1002-11.

35. Alwis G, Linden C, Stenevi-Lundgren S, et al. A one-year exercise intervention program in pre-pubertal girls does not influence hip structure. BMC Musculoskelet Disord 2008;9:9.

36. McKay HA, MacLean L, Petit M, et al. "Bounce at the Bell": a novel program of short bouts of exercise improves proximal femur bone mass in early pubertal children. Br J Sports Med 2005;39:521-6.

37. Inskip HM, Godfrey KM, Robinson SM, Law CM, Barker DJ, Cooper C SWS Study Group. Cohort profile: The Southampton Women's Survey. Int J Epidemiol 2006;35:42-8.

38. Martin RB, Burr DB. Non-invasive measurement of long bone crosssectional moment of inertia by photon absorptiometry. J Biomech 1984;17:195-201.

39. Khoo BC, Beck TJ, Qiao QH, et al. In vivo short-term precision of hip structure analysis variables in comparison with bone mineral density using paired dual-energy X-ray absorptiometry scans from multi-center clinical trials. Bone 2005;37:112-21. 